\title{
Morphoanatomical and Biochemical Changes in the Roots of Rice Plants Induced by Plant Growth-Promoting Microorganisms
}

\author{
Marcela Cristiane Ferreira Rêgo, ${ }^{1}$ Fernanda Ilkiu-Borges, ${ }^{2}$ Marta Cristina Corsi de Filippi, ${ }^{3}$ \\ Letícia Almeida Gonçalves, ${ }^{4}$ and Gisele Barata da Silva ${ }^{1}$ \\ ${ }^{1}$ Laboratório de Proteção de Plantas, Programa de Pós-Graduação em Agronomia (ICA), \\ Universidade Federal Rural da Amazônia, 66077-830 Belém, PA, Brazil \\ ${ }^{2}$ Laboratório de Botânica, Embrapa Amazônia Oriental, Belém, PA, Brazil \\ ${ }^{3}$ Laboratório de Fitopatologia, Embrapa Arroz e Feijão, 75375-000 Goiânia, GO, Brazil \\ ${ }^{4}$ Laboratório de Anatomia Vegetal, Instituto de Ciências Biológicas, Universidade Federal de Goiás, Campus II, \\ 74001-970 Goiânia, GO, Brazil \\ Correspondence should be addressed to Gisele Barata da Silva; gibarata@bol.com.br
}

Received 23 June 2014; Revised 14 October 2014; Accepted 28 October 2014; Published 25 November 2014

Academic Editor: Bernd Schneider

Copyright (C) 2014 Marcela Cristiane Ferreira Rêgo et al. This is an open access article distributed under the Creative Commons Attribution License, which permits unrestricted use, distribution, and reproduction in any medium, provided the original work is properly cited.

\begin{abstract}
The goal of the present study was to characterize anatomical and biochemical changes in rice plant roots in response to seed treatment with rhizobacteria (Burkholderia pyrrocinia (R-46) + Pseudomonas fluorescens (R-55)) and Trichoderma asperellum (Ta: mixture of strains T-06, T-09, T-12, and T-52). The experimental design was completely randomized, with six treatments (R-46, R55, R-46 + R-55, Ta+ R-46 + R-55, Ta, and control) and ten replicates. Treatments Ta and R-46 + R-55 increased the root length and diameter as well as the cortex expansion and induced a $2 \%$ expansion of the aerenchymal space. Treatments Ta and R- 46 increased the vascular cylinder diameter. The number of protoxylem poles and metaxylem vessel elements was increased by R- 46 and R- 55 . The total phenol content increased with treatments Ta, R-46 + R-55, R-46, and R-55, and all the treatments increased the flavonoid content. The lignin content increased with the Ta and R-55 treatments. All the root architecture modifications resulting from the interaction between seedlings and bioagents (rhizobacteria and Trichoderma spp.) observed in the present study favored the root plasticity of rice seedlings.
\end{abstract}

\section{Introduction}

Upland rice is planted in few regions worldwide. However, it presents advantages compared to floodland rice due to its lower production costs and water consumption. The average productivity of upland rice has been under 3 ton $\cdot \mathrm{ha}^{-1}$, whereas the productivity potential of improved cultivars is greater than 5 ton $\cdot \mathrm{ha}^{-1}$. The low productivity is attributed to water stress, which causes low initial vigor of the seedling root, deficiency in the uptake of nitrogen in the form of nitrate $\left(\mathrm{NO}_{3}{ }^{-}\right)$at early stages of rice plant development, lack of plant response to inputs under successive planting, and the occurrence of rice blast [1-3].
Biofertilizers are fertilizers composed of living microorganisms that promote plant growth when in contact with seeds or roots [4]. Plant growth-promoting rhizobacteria (PGPR) and the fungus T. asperellum are referred to in the literature as promoting plant growth through chemical signaling that elicits hormone and enzyme metabolic pathways related to oxidative stress [5], induction of structural changes in host plant cells, increases in the uptake of macronutrients such as $\mathrm{P}$ and $\mathrm{N}$, and induction of systemic resistance (ISR) [6].

Inoculation with isolates of Burkholderia pyrrocinia (R46) and Pseudomonas fluorescens (R-55) has been found to promote growth of rice plants and decrease the severity of 
rice blast (Magnaporthe oryzae) through direct antibiosis and ISR [6], and isolates of T. asperellum (T.06, T.09, T.12, and T.52), applied to seeds and sprayed on leaves, decreased the severity of rice sheath blight and increased rice biomass and productivity both in the field and in greenhouse studies [7].

The characterization of histological and biochemical changes resulting from interactions between plant growthpromoting microorganisms (PGPMs) or bioagents and plant growth is important to understand the mechanisms involved in the growth process. This knowledge will be useful for the optimization of the current production system, making it more sustainable and environmentally friendly.

Bioagents constitute a sustainable option for plant production systems. In the present study, the hypothesis was advanced that bioagents R-46, R-55, and T. asperellum promote changes at the cell and biochemical levels in roots of rice plants. The goal of the present study was to identify and characterize anatomical and biochemical changes in rice roots treated with rhizobacteria (R-46 and R-55) and T. asperellum.

\section{Materials and Methods}

2.1. Plant Material and Microorganisms. The tested P. fluorescens (R-55) and B. pyrrocinia (R-46) isolates had been previously selected by [6], and the four T. asperellum isolates (T-06, T-09, T-12, and T-52) had been selected by [7]. All the isolates were stored at $\pm 4^{\circ} \mathrm{C}$ at the microorganism bank of the Plant Protection Laboratory (Laboratório de Proteção de Plantas (LPP)) from the Rural Federal University of the Amazon (Universidade Federal Rural da Amazônia (UFRA)).

The treatments were composed of rice seeds (cultivar. Primavera Clearfield) microbiolized with T1: a mixture of four isolates of T. asperellum (T-06, T-09, T-12, and T-52); T2: two isolates of rhizobacteria, $P$. fluorescens (R-55) and $B$. pyrrocinia (R-46); T3: P. fluorescens (R-55); T4: B. pyrrocinia (R-46); T5: the microorganisms combined (all 4 isolates of T. asperellum + P. fluorescens $+B$. pyrrocinia); and T6: watertreated control.

The tested rhizobacteria (B. pyrrocinia (R.46) and $P$. fluorescens (R-55)) were separately inoculated in Petri dishes with 523 solid culture media [8] and incubated for 48 hours at $28^{\circ} \mathrm{C}$. A bacterial suspension was subsequently prepared using sterile water and adjusted at $550 \mathrm{~nm}$ absorbance using a spectrophotometer $(\mathrm{A} 550=0.1$ corresponding to $10^{8} \mathrm{CFU} \cdot \mathrm{mL}^{-1}$ ).

The four isolates of T. asperellum (T.06, T.09, T.12, and T.52) were individually grown in plastic bags, containing $50 \mathrm{~g}$ of sterilized rice grains, and incubated during 6 days at $25^{\circ} \mathrm{C}$. From each plastic bag, a sample of $10 \mathrm{~g}$ of rice colonized with $T$. asperellum was blent and homogenized. Then a conidial suspension was prepared, which was adjusted to $10^{8} \mathrm{CFU} \cdot \mathrm{mL}^{-1}$ using a Neubauer chamber.

Rice seeds were sterilized with $70 \%$ ETOH and 2\% $\mathrm{NaClO}$, both for 1 minute, washed in sterile water for 1 minute, and placed on sterile filter paper, where they remained for 1 hour. The seeds were then steeped in the suspensions for each treatment for 24 hours at $28^{\circ} \mathrm{C}$ and at $115 \mathrm{rpm}$ and were subsequently sown.
Two experiments were carried out: the first one in glass tube $(60 \mathrm{~mL})$ and the other in polyethylene plastic tube $\left(180 \mathrm{~cm}^{3}\right)$. The two experiments were completely randomized, with six treatments and ten replicates; the number of samples was 20 per treatment. The assay was performed in duplicate.

Experiment 1. After the microbiolization the seeds were sown in $60 \mathrm{~mL}$ tubes containing water-agar $\left(1 \mathrm{~L} \mathrm{H}_{2} \mathrm{O}+13.65 \mathrm{~g}\right.$ of agar), where they remained for 21 days after sowing. Twenty plants of each treatment were collected for root anatomy description.

Experiment 2. After the microbiolization the seeds were sown in $180 \mathrm{~cm}^{3}$ tubes containing Gernino plant substrate (containing pine bark, peat, acidity corrective, triple superphosphate, and potassium nitrate). To quantify the dry mass (g) and length $(\mathrm{cm})$ of leaves and roots, root/leaves ratio, and the lignin, lignin monomers, phenol, and flavonoid contents.

2.2. Anatomy Description and Morphometry. The plants were collected from the test tubes 21 days following sowing. The roots were carefully washed and taken to the Botany Laboratory of the Brazilian Enterprise for Agricultural Research (Embrapa) Eastern Amazon (Laboratório de Botânica da Embrapa Amazônia Oriental), fixed in FAA50 (50 mL of 37\% formaldehyde, $50 \mathrm{~mL}$ of glacial acetic acid, and $900 \mathrm{~mL}$ of $50 \%$ ethanol), and subjected to vacuum in a desiccator for 24 hours. The fixative was then discarded, and the roots were stored in $70 \%$ ethanol until further processing.

Part of the samples was rehydrated in a graded ethanolic series to obtain sections [9] and analyzed by optical microscopy. Ten free-hand cross-sections were obtained from roots. The sections were cleared in sodium hypochlorite $2 \% \mathrm{NaClO}$ for 1 minute, placed in 1\% Astrablau for 30 seconds, and then placed in 1\% Basic Fuchsin. Measurements were performed using a millimetric eyepiece on a Motic BA-400 microscope. In addition to the anatomical description, the root diameter, expansion of the cortex, thickness of the exodermis, and diameter of vascular cylinder were measured, and the numbers of protoxylem poles and metaxylem vessel elements were quantified.

Another part of the samples was dehydrated in a graded increasing ethanolic series, critical point-dried $\left(\mathrm{CO}_{2}\right)$, coated with a thin layer of gold, and observed using a scanning electron microscope (SEM). Cross-sections were obtained from the roots of three plants per treatment. The images obtained were used to determine the area occupied by the aerenchyma using the ANTI QUANT 2 software.

2.3. Dry Mass Gain and Length. Twenty-one days after growth, ten plants were collected from each treatment, and the following measurements were performed: leaf and root length, root/leaf ratio $(\mathrm{cm})$, dry mass of leaves and roots, and root/leaf ratio $(\mathrm{g})$. The dry mass was measured following drying of the plant material in a forced air circulation oven for 7 days at $65^{\circ} \mathrm{C}$, using an analytical scale. 


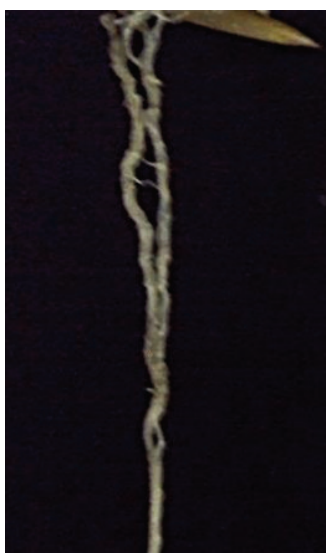

(a)

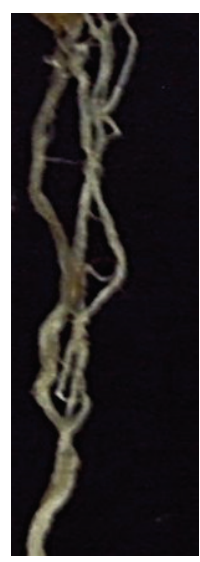

(b)

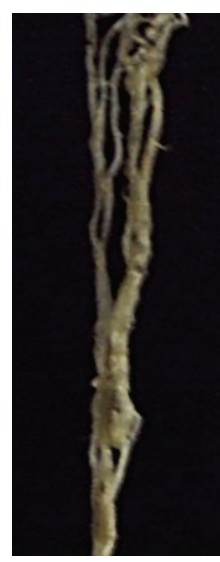

(c)

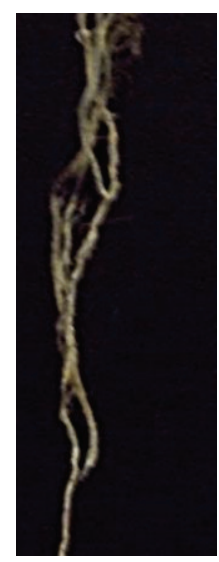

(d)

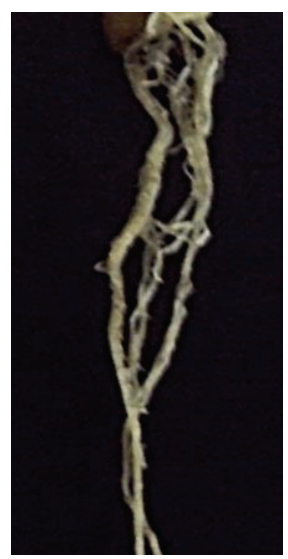

(e)

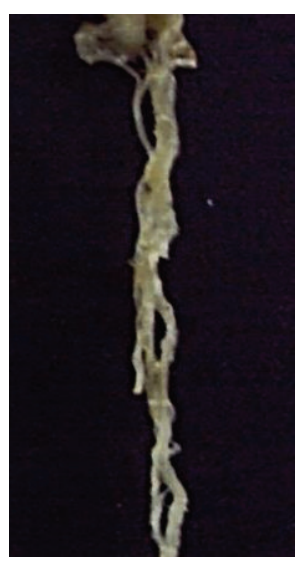

(f)

FIGURE 1: Adventitious roots of rice plants originating from microbiolized seeds. (a) Control plant (nonmicrobiolized seeds). (b-f) Roots of plants from seeds microbiolized with (b) T. asperellum (T-06, T-09, T-12, and T-52) + B. pyrrocinia + P. fluorescens, (c) T. asperellum (T-06, T-09, T-12, and T-52), (d) B. pyrrocinia + P. fluorescens, (e) B. pyrrocinia, and (f) P. fluorescens (f). Evaluation was performed 9 days after sowing.

\subsection{Determination of Phenols, Flavonoids, Lignin, and Lignin} Monomers. Ten plants of each treatment were collected, and three replicates were performed, for each evaluation. Roots were separated from the shoot, washed, and placed in a forced air circulation oven at $65^{\circ} \mathrm{C}$ for 7 days, until a constant mass was reached. The roots were then ground using liquid nitrogen and stored at $\pm 4^{\circ} \mathrm{C}$.

Total lignin and lignin monomers: samples were homogenized in $50 \mathrm{mM}$ sodium phosphate buffer, $\mathrm{pH} 7.0$, purified in $1 \%$ Triton $\mathrm{X}-100,1 \mathrm{M} \mathrm{NaCl}$, and acetone, according to [10], and centrifuged for 15 minutes. The final pellet was dried and considered to be the protein freed from cell walls. Lignin was quantified using the thioglycolic acid method [10], and lignin monomers were quantified using alkaline nitrobenzene peroxidation [11].

Total phenols and flavonoids: one gram of root was extracted in $20 \mathrm{~mL}$ methanol $(80: 20, \mathrm{v} / \mathrm{v})$ for 15 minutes, and the extract was resuspended in $20 \mathrm{~mL}$ of $1 \%$ Triton $\mathrm{X}-100$. The extract was used for the determination of the total phenol content using a spectrophotometer (absorbance $735 \mathrm{~nm}$ ). A standard curve was obtained using gallic acid. Flavonoid contents were determined in extracts in aluminum chloride by a colorimetric assay (735 $\mathrm{nm})$ [12].

2.5. Statistical Analysis. An ANOVA was performed, followed by a Duncan test $(P<0.05$ and $P<0.1)$, and the standard error was calculated $(P \leq 0.05)$. The SPSS 17.0 software was used for all the analyses.

\section{Results}

3.1. Dry Mass and Length Gain. The root length and dry mass of plants treated with biopromoters were higher than control treatment. Significant differences in root length and root/leaf ratio were observed among the treatments with seeds microbiolized with the four T. asperellum isolates and the combination of the two rhizobacteria (B. pyrrocinia $+P$. fluorescens) (Table 1).

Plants treated with the mix of the four T. asperellum isolates presented higher leaf and root dry mass, when compared to the other treatments. The root/leaf dry mass was higher for all biopromoter treatments (Table 1).

3.2. Anatomy Description and Morphometry. The root diameter increased in all the treatments with PGPMs. This change was especially pronounced for the treatments with $B$. pyrrocinia and with T. asperellum $+B$. pyrrocinia $+P$. fluorescens, for which statistically significant differences from the control were observed (Table 2).

Plants originating from seeds microbiolized with PGPMs presented more adventitious roots, based on visual assessments, compared to control plants (Figure 1, Table 1). In addition, SEM observations (Figure 2) and morphometry revealed that some of the anatomical characteristics of the roots changed, such as vascular cylinder diameter, cortex and exodermis thickness, and number of protoxylem poles and metaxylem vessel elements (Figure 2).

The cortex and exodermis thickness and number of protoxylem poles were significantly higher in the roots of all the PGPM treatments. The treatments with B. pyrrocinia and with $B$. pyrrocinia $+P$. fluorescens statistically presented the largest increase in cortex thickness and in the number of poles of protoxylem, respectively (Table 2 ).

The lacunae of aerenchyma area and the number of metaxylem vessel elements increased in all the treatments with PGPMs, except for the treatment with the rhizobacteria (R-55 and R-46) and T. asperellum mix (Table 2), which were not significantly different from the control roots (Table 2).

3.3. Determination of Phenols, Flavonoids, Lignin, and Lignin Monomers. The total phenol and flavonoid contents increased in all the plants treated with bioagents (Table 3), except for the treatment with B. pyrrocinia + P. fluorescens, 


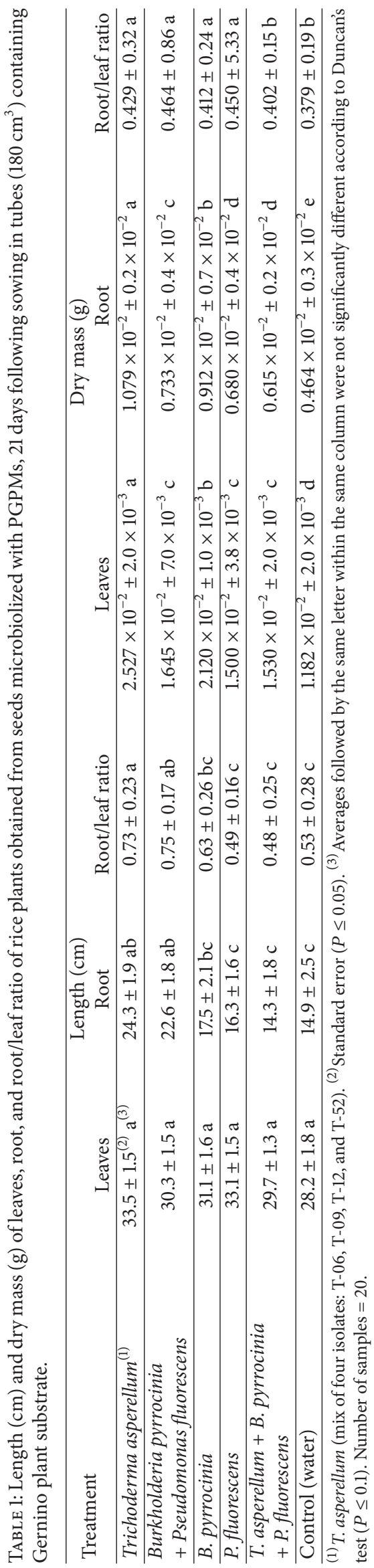




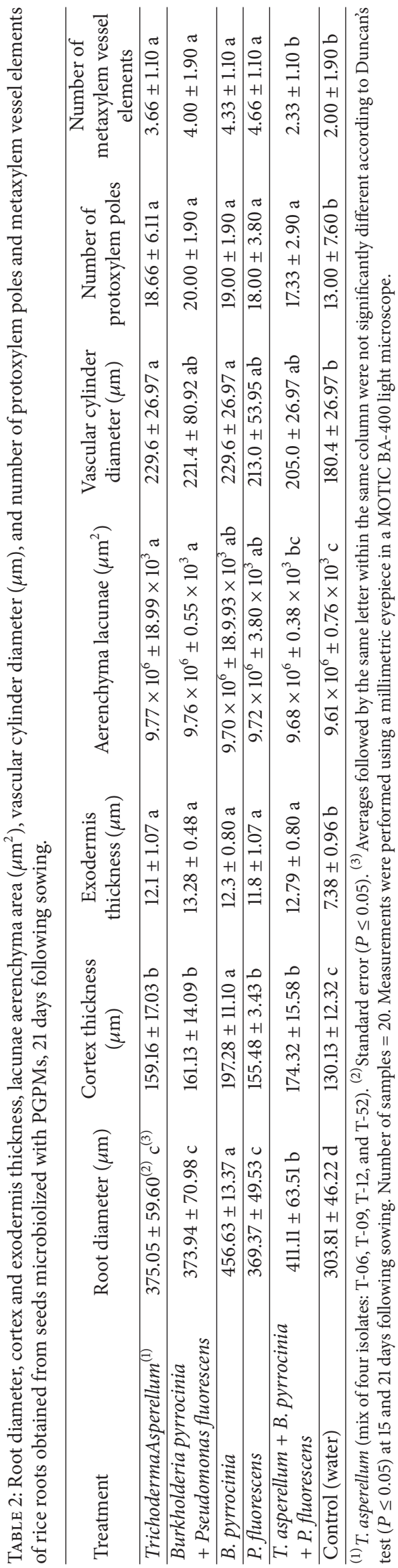




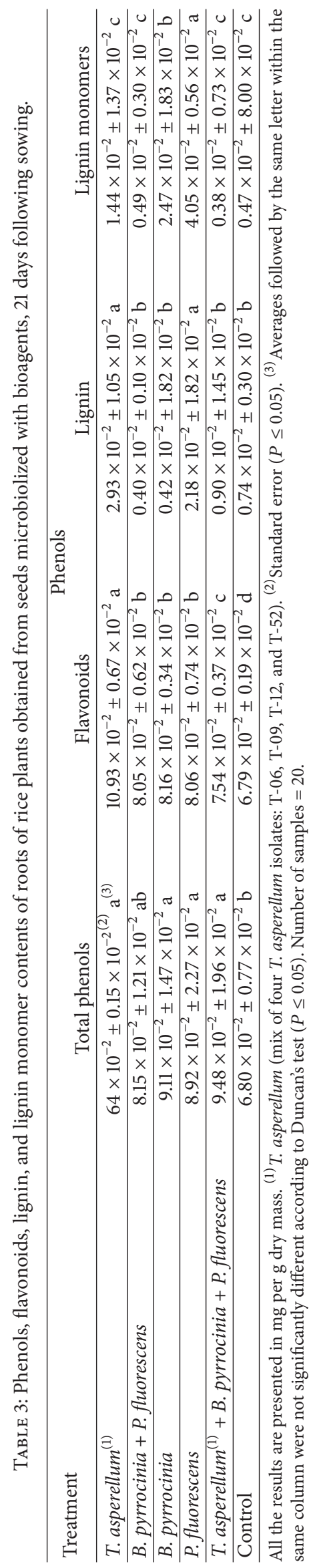




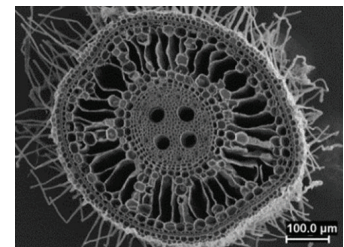

(a1)

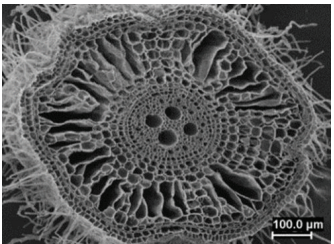

(b1)

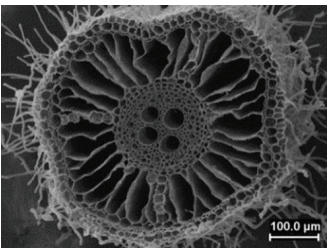

(c1)

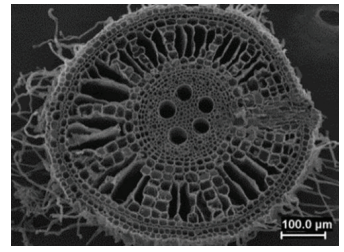

(d1)

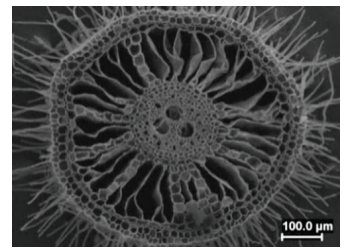

(e1)

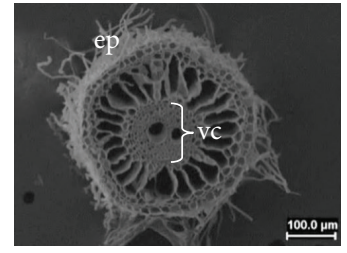

(f1)

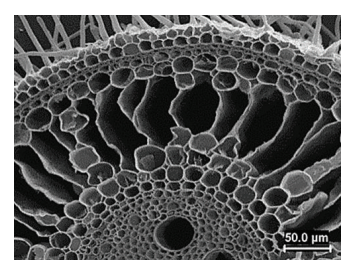

(a2)

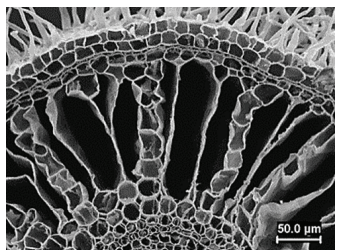

(b2)

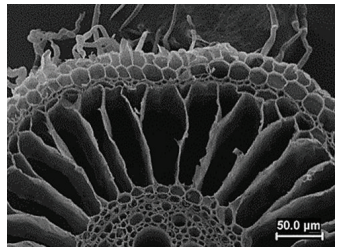

(c2)

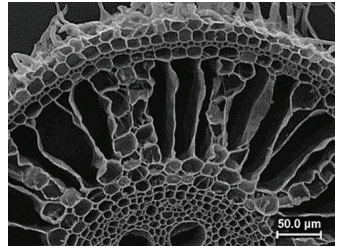

(d2)

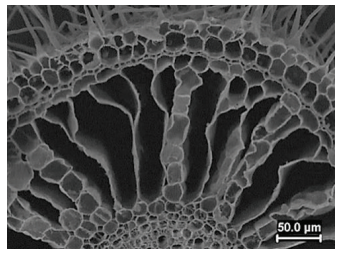

(e2)

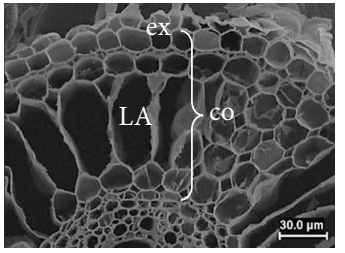

(f2)

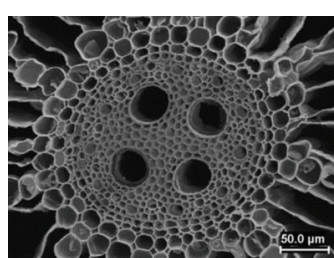

(a3)

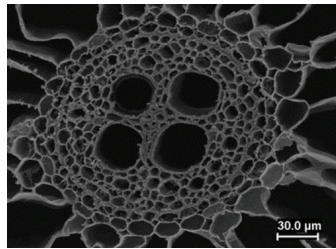

(b3)

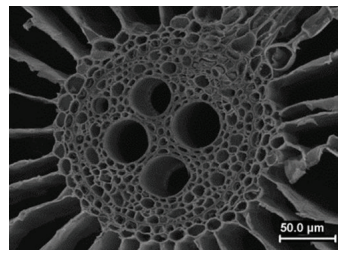

(c3)

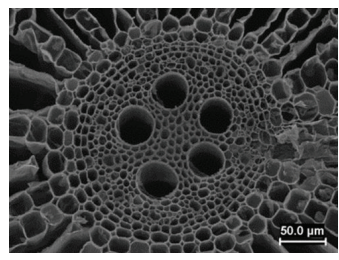

(d3)

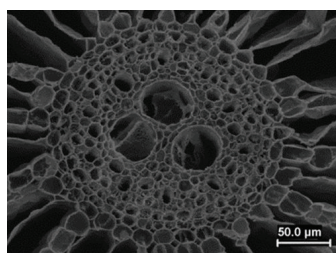

(e3)

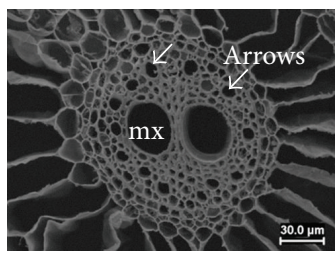

(f3)

Figure 2: Electromicrographs of adventitious roots of rice obtained from seeds treated with PGPMs, 21 days following sowing. (a1-a3) T. asperellum (T-06, T-09, T-12, and T-52), (b1-b3) B. pyrrocinia + P. fluorescens, (c1-c3) B. pyrrocinia, (d1-d3) P. fluorescens, (e1-e3) T. asperellum (T-06, T-09, T-12, and T-52) + B. pyrrocinia + P. fluorescens, and (f1-f3) control. Epidermis with root hairs (ep), cortex (co), aerenchyma lacunae (LA), exodermis (ex), vascular cylinder (vc), protoxylem poles (arrows), and metaxylem vessel elements (mx).

which presented a phenol content similar to that of the control. However, the lignin content only increased in the roots of the plants treated with T. asperellum and P. fluorescens isolates. Microbiolization of seeds with $P$. fluorescens resulted in the higher expression of lignin monomers, followed by the seeds treated with $B$. pyrrocinia. The remaining treatments were not significantly different from the control (Table 3).

\section{Discussion}

Treatment with $T$. asperellum ( $\mathrm{mix}$ of four T. asperellum isolates: T-06, T-09, T-12, and T-52) and the combination of rhizobacteria (B. pyrrocinia + P. fluorescens) resulted in 58 and $43 \%$ gain in root length of rice seedlings, respectively, and T. asperellum resulted in $46 \%$ increase in root/leaves ratio 
(Table 1). These results are, probably, explained by the fact that T. asperellum isolates T-06, T-09, T-12, and T-52 were reported to produce phosphate-solubilizing enzymes, and among them T-12 and T-52 were identified as auxins producers. The same isolates also decrease rice sheath blight (Rhizoctonia solani) severity by $43 \%$, a sclerotide viability up to $50 \%$, and the area under the disease progress curve by $45 \%$ (Silva et al., 2012) [7]. It was earlier observed that isolates R-55 and R-46 were siderophores producers, besides $\beta-1,3-$ glucanase during rice blast severity suppression [6].

These root modifications promoted by PGPMs result in positive physiological responses of plants. This response was observed in Carthamus tinctorius L. treated with Azotobacter vinelandii and Azospirillum brasilense, which presented up to $76 \%$ gain in root diameter, resulting in greater biomass [13]. When the PGPMs were combined with chemical fertilizers applied every three months, a maximum $64 \%$ gain in root diameter was observed compared to the control [14]. These modifications of the root system in response to the PGPMs may be associated with changes in signaling in phytohormone pathways, such as indol-3-acetic acid (IAA), resulting in increases of the surface area and the number of roots and root hairs. Parallel to the increase in root system induced by PGPRs and T. asperellum, an increase in mineral ion translocation via stimulation of ATPase proton pumps has been suggested [15]. The root gains induced by the PGPMs tested in the present study, T. asperellum and PGPRs, are very important for upland rice production systems. In this planting system, rice is limited due to the low vigor of the plant during the first 21 days following sowing. This limitation is a consequence of the low efficiency in $\mathrm{N}$ uptake due to the higher levels of $\mathrm{N}$ available in the form of $\mathrm{NO}_{3}{ }^{-}$[1] and to the fact that rice plants take up ammonium $\left(\mathrm{NH}_{4}{ }^{+}\right)$with higher efficiency [3]. Nitrogen influences the formation of roots at the meristematic tissues of the root-elongation region [16].

All the tested PGPMs resulted in an expansion of the root cortex up to $30 \%$ and of the exodermis up to $68 \%$ compared to the control, 21 days following sowing. This change was more pronounced for B. pyrrocinia and the combination of the two rhizobacteria (B. pyrrocinia $+P$. fluorescens), for which differences were observed starting 15 days following sowing. The exodermis constitutes barriers to the radial movement of ions and water at the roots [17]. A greater expansion of those layers induced by PGPMs may confer to the rice plants adequate levels of nutrients, especially $\mathrm{K}^{+}, \mathrm{Ca}^{2+}$, and $\mathrm{Mg}^{2+}$, lower loss of water, resulting in better maintenance of physiological and metabolic activities of plants, and greater resistance to water and salt stress $[18,19]$. The aerenchyma lacunae increased up to $2 \%$ in plants treated with T. asperellum and B. pyrrocinia $+P$. fluorescens. Increasing the aerenchymal lacunae is very important for rice root in upland conditions, probably for helping adaptation during drought periods [20]. The aerenchyma expansion results in greater gas exchange for the irrigated rice plants and is mediated by the formation of reactive oxygen species (ROS). ROS have been identified as a signal required for cell death to occur at the cortex, which is induced by ethylene [21-23].
Ethylene was identified as the hormonal signal mediating formation of aerenchyma in corn and rice [24, 25]. However, in corn, root cortical aerenchyma reduces root respiration by converting living cortical tissue to air volume and increases drought tolerance by reducing root metabolic costs, permitting greater root growth and water acquisition from drying soil [26]. Our data makes us believe that in rice the same results could be found.

The vascular cylinder diameter increased $27 \%$ in the treatments with T. asperellum (mix of four isolates: T-06, T09, T-12, and T-52) and B. pyrrocinia. All the tested PGPMs increased the number of protoxylem poles (43\% in average). The number of metaxylem vessel elements increased $108 \%$ in the plants treated with T. asperellum (mix of four isolates: T-06, T-09, T-12, and T-52), B. pyrrocinia + P. fluorescens, B. pyrrocinia, and $P$. fluorescens (Table 2). Rice genotypes with more xylem vessels present better water conduction and will be more tolerant to water stress under Indian summer conditions. Some studies showed that increasing the number and the diameter of xylem vessels promotes drought resistance in legumes such as chickpeas (Cicer arietinum L.), peanuts (Arachis hypogaea L.), pigeon pea (Cajanus cajan (L.) Millsp.), cowpea (Vigna unguiculata (L.) Walp.), soybean (Glycine max (L.) Merr.), common bean (Phaseolus vulgaris L.), and millet (Pennisetum glaucum (L.) R. Br.) [27, 28]. This tolerance may result in higher productivity compared to plants not treated with PGPMs in upland systems [29, 30]. The occurrence of Indian summers in the savanna results in plant water stress, which may be minimized by anatomical adaptations. Studies have shown that some anatomical root characteristics, such as the metaxylem vessel elements diameter, are related to the maintenance of water conduction [31].

The plants treated with $B$. pyrrocinia presented a thicker pericycle than the remaining treatments (Figures 2(a3)$2(\mathrm{f} 3))$. The pericycle is related to the formation of lateral roots (Figure 1), which play an important role in plant development, facilitating oxygen diffusion from the base to the apex as well as water, ion, and nutrient uptake $[32,33]$, allowing the construction of ramified root systems. The process of lateral root formation consists of two main stages: reactivation of the pericycle cell cycle and establishment of a new meristem [34]. In Arabidopsis, lateral roots are initiated by the local activation of pericycle cells and of the protoxylem poles [35]. In the present study, the tested PGPMs stimulated all these cells, pericycle and protoxylem, which may result in increased lateral root formation and consequently more vigorous establishment of rice plants.

All the tested PGPMs increased the levels of at least two phenols in roots. The maximum total phenol content was $42 \%$ in the plants treated with $T$. asperellum, and the average increase in flavonoids for all the treatments was $26 \%$ (Table 3). The increase in total phenols and flavonoids in plants treated with Trichoderma starts with the host plant root penetration and colonization by Trichoderma. At that moment, the plant increases the production of phenols to restrict the Trichoderma spp. colonization of the intercellular spaces at the epidermis, cortex, and vascular bundles. However, some isolates of this fungus can tolerate the increase in concentration of antimicrobial compounds inside the cell and 
keep growing intra- and intercellularly at the roots of treated plants. This tolerance has been associated with the presence of ion-transport systems, which are key factors of the multiple effects of Trichoderma species as biocontrol and growthpromoting agents [36, 37]. Biotic and abiotic factors are known to induce systemic resistance (ISR) through structural changes. The physical and mechanical strength of the cell wall is induced by several factors and is generally expressed first as a hypersensitivity reaction (HR) to the penetration of phytopathogen cells. This reaction leads to histological changes, such as formation of papillae, lignification, deposition of callose, and thickening of the cell wall due to deposition of phenols and substances similar to hydrogen peroxide [38].

The increase in lignin content was approximately $300 \%$ in the plants treated with T. asperellum (mix of four isolates: T06, T-09, T-12, and T-52) and 200\% in the plants treated with P. fluorescens. The highest accumulation of lignin monomers was observed in the plants treated with P. fluorescens (762\%) (Table 3). Lignocellulosic biomass is composed of cellulose, hemicellulose, and lignin, and lignin is the most recalcitrant to biodegradation [39]. The increase of these polymers may confer better organization of macrofibrils, which mediate the structural stability of the root cell wall, to rice roots treated with T. asperellum and P. fluorescens [40].

The rhizobacteria $P$. fluorescens presented biofilm formation, which helps the bacteria attach to roots of rice seedlings. This benefit of biofilm formation was shown in roots of Arabidopsis thaliana, where the inhibition of biofilm formation at the root surface resulted in decreased adhesion of Bacillus subtilis to the substrate surface and could lead to the produced catechol (phenol), which can generate reactive oxygen species [41]. Studies with Arabidopsis and rice showed that catechol induces higher levels of superoxide $\mathrm{H}_{2} \mathrm{O}_{2}[42,43]$.

\section{Conclusions}

All the root architecture modifications resulting from the interaction between seedlings and bioagents (rhizobacteria and Trichoderma spp.) observed in the present study favored the root plasticity of rice seedlings, resulting in greater plant growth due to a better water uptake, resistance to water stress, and mechanical impedance. The tested bioagents were shown to be potential biofertilizer to be inserted in upland rice management, with the goal of minimizing the disadvantages of this system, besides increasing defense response and increasing the productivity levels of genetically improved rice cultivars, without increasing the application of chemicals for fertilization and plant protection.

\section{Abbreviations}

Embrapa: Brazilian Enterprise for Agricultural Research

HR: Hypersensitivity reaction

IAA: Indol-3-acetic acid

ISR: Induced systemic resistance

PGPMs: Plant growth-promoting microorganisms

PGPR: Plant growth-promoting rhizobacteria

ROS: $\quad$ Reactive oxygen species

SEM: $\quad$ Scanning electron microscopy.

\section{Conflict of Interests}

The authors declare that there is no conflict of interests regarding the publication of this paper.

\section{Acknowledgments}

The authors thank the National Council for Scientific and Technological Development (Conselho Nacional de Desenvolvimento Científico e Tecnológico (CNPq)), Amazon Research Foundation (Fundação Amazônia Paraense de Amparo à Pesquisa (Fapespa)), and the Rural Federal University of Amazon (Universidade Federal Rural da Amazônia (UFRA)) for the research funding and the Brazilian Federal Agency for the Support and Evaluation of Graduate Education (Coordenação de Aperfeiçoamento de Pessoal de Nível Superior (CAPES)) for the granting of a Master's scholarship.

\section{References}

[1] A. F. D’Andréa, M. L. N. Silva, N. Curi, and L. R. G. Guilherme, "Estoque de carbono e nitrogênio e formas de nitrogênio mineral em um solo submetido a diferentes sistemas de manejo," Pesquisa Agropecuária Brasileira, vol. 39, pp. 179-186, 2004.

[2] X. Qian, Q. Shen, G. Xu, J. Wang, and M. Zhou, "Nitrogen form effects on yield and nitrogen uptake of rice crop grown in aerobic soil," Journal of Plant Nutrition, vol. 27, no. 6, pp. 10611076, 2004

[3] J. L. Araújo, Atividade da redutase do nitrato sobre o crescimento e a produção de arroz [M.S. thesis], Universidade Federal de Lavras-UFLA, Lavras, Brazil, 2004.

[4] J. K. Vessey, "Plant growth promoting rhizobacteria as biofertilizers," Plant and Soil, vol. 255, no. 2, pp. 571-586, 2003.

[5] S. N. Raj, S. N. Lavanya, K. N. Amruthesh, S. R. Niranjana, M. S. Reddy, and H. S. Shetty, "Histo-chemical changes induced by PGPR during induction of resistance in pearl millet against downy mildew disease," Biological Control, vol. 60, no. 2, pp. 90102, 2012.

[6] M. C. C. Filippi, G. B. da Silva, V. L. Silva-Lobo, M. V. C. B. Côrtes, A. J. G. Moraes, and A. S. Prabhu, "Leaf blast (Magnaporthe oryzae) suppression and growth promotion by rhizobacteria on aerobic rice in Brazil," Biological Control, vol. 58, no. 2, pp. 160-166, 2011.

[7] J. C. Silva, D. B. Torres, D. C. Lustosa, M. C. C. Filippi, and G. B. Silva, "Rice sheath blight biocontrol and growth promotion by Trichoderma isolates from the Amazon," Revista de Ciências Agrárias, vol. 55, pp. 243-250, 2012.

[8] C. I. Kado and M. G. Heskett, "Selective media for isolation of Agrobacterium, Corynebacterium, Erwinia, Pseudomonas, and Xanthomonas," Phytopathology, vol. 60, no. 6, pp. 969-976, 1970.

[9] D. A. Johansen, Plant Microtechnique, McGraw Hill, New York, NY, USA, 1940.

[10] J. Kováčik and B. Klejdus, "Dynamics of phenolic acids and lignin accumulation in metal-treated Matricaria chamomilla roots," Plant Cell Reports, vol. 27, no. 3, pp. 605-615, 2008.

[11] B. Van Der Rest, S. Danoun, A.-M. Boudet, and S. F. Rochange, "Down-regulation of cinnamoyl-CoA reductase in tomato (Solanum lycopersicum L.) induces dramatic changes in soluble phenolic pools," Journal of Experimental Botany, vol. 57, no. 6, pp. 1399-1411, 2006. 
[12] S. F. AbouZid and G. M. Elsherbeiny, "Increase in flavonoids content in red onion peel by mechanical shredding," Journal of Medicinal Plant Research, vol. 2, pp. 258-260, 2008.

[13] D. M. Eissenstat and R. D. Yunai, "Root life span, efficiency and turnover," in Plant Roots: The Hidden Half, Y. Waisel, A. Eshel, and U. Kafkafi, Eds., pp. 339-366, Marcel Dekker, New York, NY, USA, 3rd edition, 2012.

[14] A. Nosheen, A. Bano, F. Ullah, U. Farooq, H. Yasmin, and I. Hussain, "Effect of plant growth promoting rhizobacteria on root morphology of safflower (Carthamus tinctorius L.)," African Journal of Biotechnology, vol. 10, no. 59, pp.12669-12679, 2011.

[15] S. Mantelin and B. Touraine, "Plant growth-promoting bacteria and nitrate availability: impacts on root development and nitrate uptake," Journal of Experimental Botany, vol. 55, no. 394, pp. 27-34, 2004.

[16] G. Chen, S. Guo, H. J. Kronzucker, and W. Shi, "Nitrogen use efficiency (NUE) in rice links to $\mathrm{NH}_{4}^{+}$toxicity and futile $\mathrm{NH}_{4}^{+}$ cycling in roots," Plant and Soil, vol. 369, no. 1-2, pp. 351-363, 2013.

[17] D. H. Reinhardt and T. L. Rost, "Salinity accelerates endodermal development and induces an exodermis in cotton seedling roots," Environmental and Experimental Botany, vol. 35, no. 4, pp. 563-574, 1995.

[18] M. R. Momayezi, A. R. Zaharah, and M. M. Hanafi, "The effects cation ratios on root lamella suberization in rice ( Oryza sativa L.) with contrasting salt tolerance," International Journal of Agronomy, vol. 2012, Article ID 769196, 8 pages, 2012.

[19] A. Razaque Memon, M. Saccomani, and A. D. M. Glass, "Efficiency of potassium utilization by barley varieties: the role of subcellular compartmentation," Journal of Experimental Botany, vol. 36, no. 12, pp. 1860-1876, 1985.

[20] R. R. Suralta and A. Yamauchi, "Root growth, aerenchyma development, and oxygen transport in rice genotypes subjected to drought and waterlogging," Environmental and Experimental Botany, vol. 64, no. 1, pp. 75-82, 2008.

[21] H. S. Han and K. D. Lee, "Plant growth promoting rhizobacteria effect on antioxidant status, photosynthesis, mineral uptake and growth of lettuce under soil salinity," Research Journal of Agricultural and Biological Science, vol. 1, pp. 210-215, 2005.

[22] M. Shoresh, G. E. Harman, and F. Mastouri, "Induced systemic resistance and plant responses to fungal biocontrol agents," Annual Review of Phytopathology, vol. 48, pp. 21-43, 2010.

[23] B. Steffens, T. Geske, and M. Sauter, "Aerenchyma formation in the rice stem and its promotion by $\mathrm{H}_{2} \mathrm{O}_{2}$," New Phytologist, vol. 190, no. 2, pp. 369-378, 2011.

[24] M. B. Jackson, T. M. Fenning, M. C. Drew, and L. R. Saker, "Stimulation of ethylene production and gas-space (aerenchyma) formation in adventitious roots of Zea mays L. by small partial pressures of oxygen," Planta, vol. 165, no. 4, pp. 486-492, 1985.

[25] S. H. F. W. Justin and W. Armstrong, "Evidence for the involvement of ethylene in aerenchyma formation in adventitious roots of rice (Oryza sativa L.)," New Phytologist, vol. 118, pp. 49-62, 1991.

[26] J. Zhu, K. M. Brown, and J. P. Lynch, "Root cortical aerenchyma improves the drought tolerance of maize (Zea mays L.)," Plant, Cell and Environment, vol. 33, no. 5, pp. 740-749, 2010.

[27] B. Choat, A. R. Cobb, and S. Jansen, "Structure and function of bordered pits: new discoveries and impacts on whole-plant hydraulic function," New Phytologist, vol. 177, no. 3, pp. 608626, 2008.
[28] R. Purushothaman, M. Zaman-Allah, N. Mallikarjuna, R. Pannirselvam, L. Krishnamurthy, and C. L. L. Gowda, "Root anatomical traits and their possible contribution to drought tolerance in grain legumes," Plant Production Science, vol. 16, no. 1, pp. 1-8, 2013.

[29] A. K. G. M. E. Haque, A comparative study of the root characteristics of aus and hill rices of Bangladesh [M.S. thesis], Central Luzon State University, 1985.

[30] A. A. Abd Allah, A. B. Shima, B. A. Zayed, and A. A. El Gohary, "The role of root system traits in the drought tolerance of rice (Oryza sativa L.)," World Academy of Science, Engineering and Technology, vol. 4, pp. 1142-1146, 2010.

[31] V. Sibounheuang, J. Basnayake, and S. Fukai, "Genotypic consistency in the expression of leaf water potential in rice (Oryza sativa L.)," Field Crops Research, vol. 97, no. 2-3, pp. 142-154, 2006.

[32] T. D. Colmer, "Long-distance transport of gases in plants: a perspective on internal aeration and radial oxygen loss from roots," Plant, Cell and Environment, vol. 26, no. 1, pp. 17-36, 2003.

[33] L. Kotula, K. Ranathunge, and E. Steudle, "Apoplastic barriers effectively block oxygen permeability across outer cell layers of rice roots under deoxygenated conditions: roles of apoplastic pores and of respiration," New Phytologist, vol. 184, no. 4, pp. 909-917, 2009.

[34] J. E. Malamy and P. N. Benfey, "Organization and cell differentiation in lateral roots of Arabidopsis thaliana," Development, vol. 124, no. 1, pp. 33-44, 1997.

[35] T. Beeckman, S. Burssens, and D. Inzé, "The peri-cell-cycle in Arabidopsis," Journal of Experimental Botany, vol. 52, pp. 403411, 2001.

[36] M. Ruocco, S. Lanzuise, F. Vinale et al., "Identification of a new biocontrol gene in Trichoderma atroviride: the role of an ABC transporter membrane pump in the interaction with different plant-pathogenic fungi," Molecular Plant-Microbe Interactions, vol. 22, no. 3, pp. 291-301, 2009.

[37] R. Hermosa, A. Viterbo, I. Chet, and E. Monte, "Plant-beneficial effects of Trichoderma and of its genes," Microbiology, vol. 158, no. 1, pp. 17-25, 2012.

[38] D. J. Maclean and I. C. Tommerup, "Histology and physiology of compatibility and incompatibility between lettuce and the downy mildew fungus, Bremia lactucae Regel," Physiological Plant Pathology, vol. 14, no. 3, pp. 294-300, 1979.

[39] D. Martinez, L. F. Larrondo, N. Putnam et al., "Erratum: Genome sequence of the lignocellulose degrading fungus Phanerochaete chrysosporium strain RP78," Nature Biotechnology, vol. 22, no. 6, pp. 695-700, 2004.

[40] E. M. Rubin, "Genomics of cellulosic biofuels," Nature, vol. 454, no. 7206, pp. 841-845, 2008.

[41] K. Muzandu, Z. Shaban, M. Ishizuka, A. Kazusaka, and S. Fujita, "Nitric oxide enhances catechol estrogen-induced oxidative stress in LNCaP cells," Free Radical Research, vol. 39, no. 4, pp. 389-398, 2005.

[42] S. C. M. Van Wees and J. Glazebrook, "Loss of non-host resistance of ArabidopsisNahG to Pseudomonas syringae pv. phaseolicola is due to degradation products of salicylic acid," Plant Journal, vol. 33, no. 4, pp. 733-742, 2003.

[43] Y. Yang, M. Qi, and C. Mei, "Endogenous salicylic acid protects rice plants from oxidative damage caused by aging as well as biotic and abiotic stress," The Plant Journal, vol. 40, no. 6, pp. 909-919, 2004. 

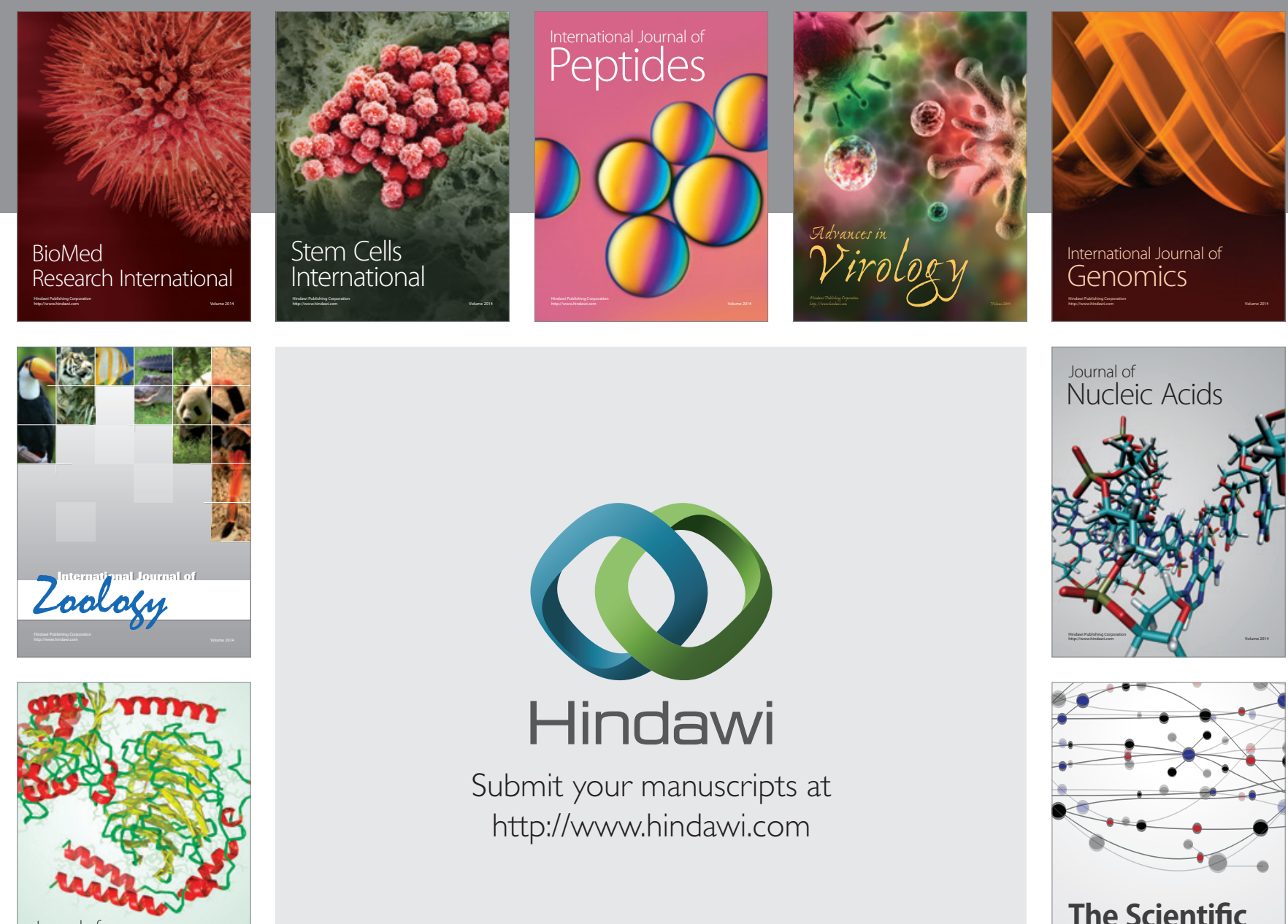

Submit your manuscripts at

http://www.hindawi.com

Journal of
Signal Transduction
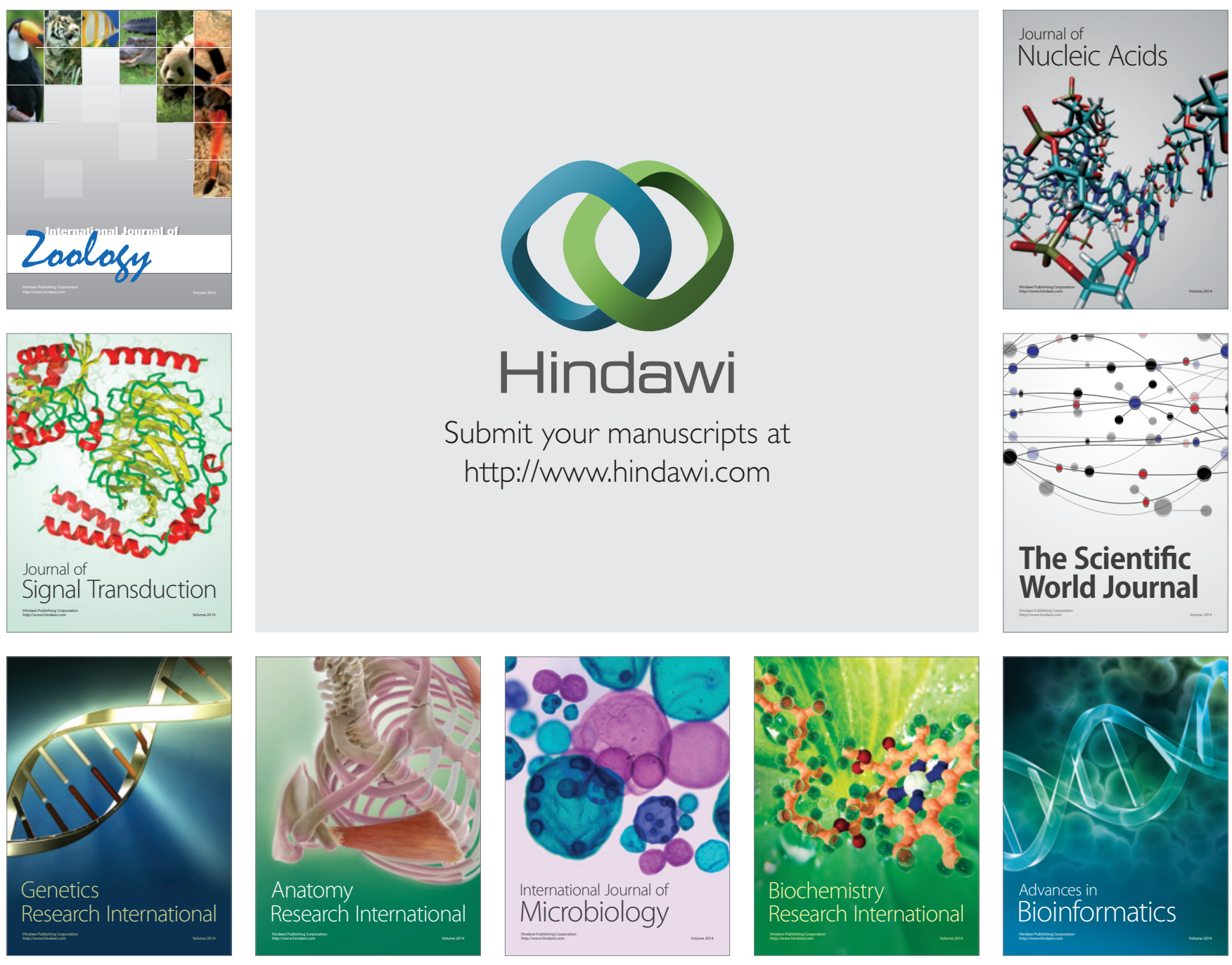

The Scientific World Journal
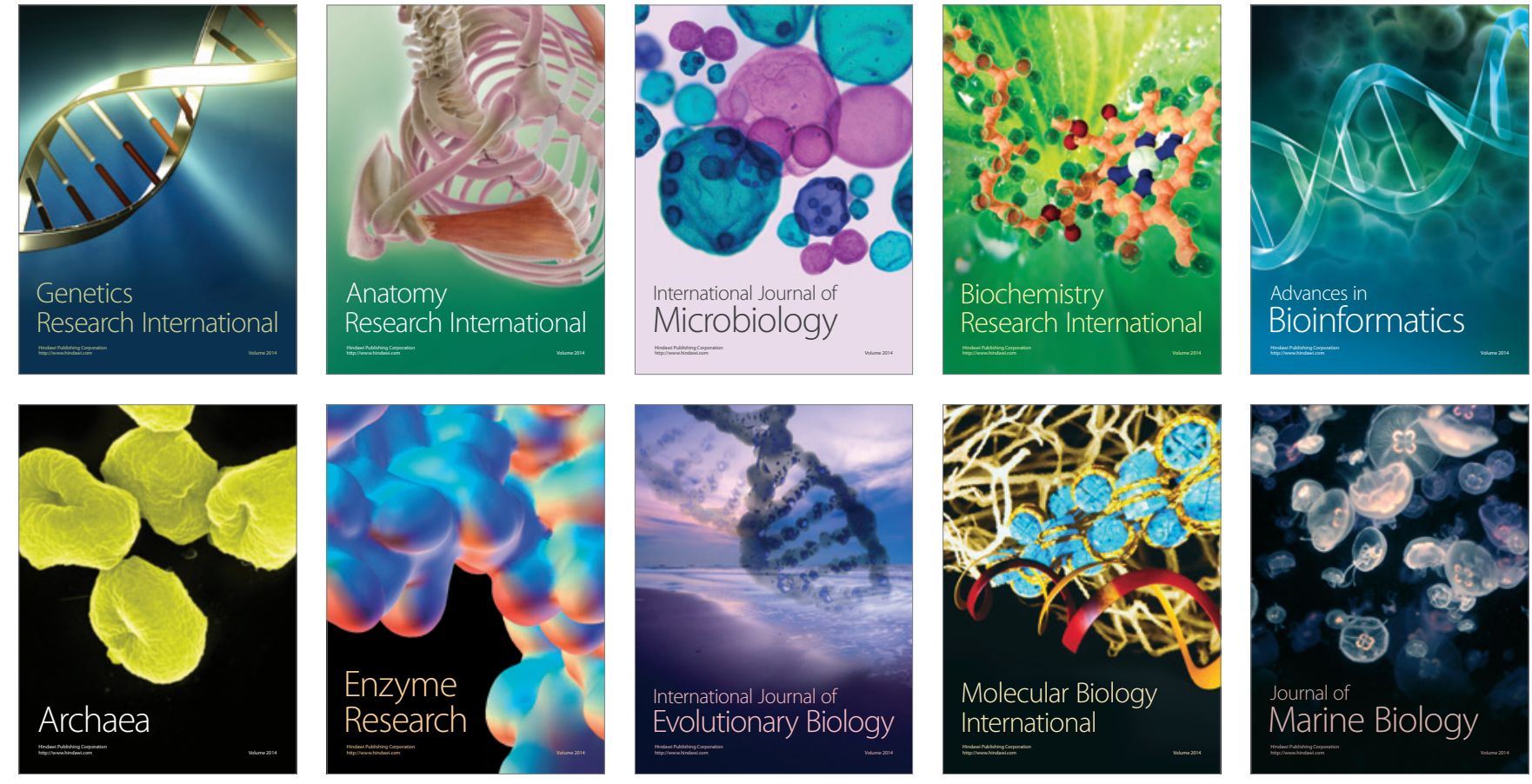